\title{
The recent evolution of UK drug strategies: from maintenance to behaviour change?
}

\author{
Mark Monaghan* \\ University of Leeds
}

\begin{abstract}
Politically, the idea that certain kinds of drugs and drug use are intrinsically linked to certain kinds of criminality - known as the drugs-crime nexus - enjoys continuing salience. This shows little sign of abating. Since 1995, successive strategies have embraced this theme and policies have been developed to try and increase the numbers of drug users entering treatment in a bid to drive down crime rates. Drawing on a review of the relevant literature and an analysis of successive drug strategies and related policy documents, this paper argues that although contemporary drug policy is still underpinned by such notions the suggested means by which crime rates are to be reduced is gradually shifting. Since 2008 , there has been a notable change in rhetoric with an increasing use of conditionality in the benefits system coupled with an overt desire to 'nudge' those engaging in risky behaviours to amend their ways. This seems to be related to a steady disillusionment with methadone maintenance treatment and a desire to solve the drug-crime problem by promoting the goal of 'abstinence'. More recently, abstinence has been replaced by the less well-defined term 'recovery', but both signal a desire for drug treatment to move away from maintenance. This paper argues that such developments are part of a creeping moralisation that has reemerged in UK social policy over recent decades.
\end{abstract}

Keywords: Drugs, Crime, Treatment, Maintenance, Abstinence, Recovery.

\section{Introduction}

In 1995 , the Conservative government published its national ${ }^{1}$ drugs strategy Tackling Drugs Together (Department of Health, 1995). This was very much a product of its time (McLaughlin et al., 2001). Drawing on political debates taking place in the United States and in reaction to some high-profile events such as the murder of James Bulger, the two largest parties in the UK decided that a more hard-line approach to crime by 'returning to justice' was the solution. In January 1993, the then shadow Home Secretary Tony Blair famously declared that New Labour would get 'tough on crime and tough on the causes of crime' and in same year the then Home Secretary, Michael Howard in his speech at the Conservative Party conference, outlined a number of 'law and order' measures to control crime, which, according to Hughes and Anthony 
(2006: 81), 'included substantial revisions' to current policy and practice working with drug users.

Howard's interjection can be seen as a blow to the principles of harm reduction prominent in UK drug policy at this point. In this context, harm reduction was based on containing, rather than eradicating the problems associated with certain drugs. Towards the end of the 1980s and into the 1990s, UK drug policy had been influenced by the view that certain kinds of drug use, particularly those involving intravenous (IV) administration, had the potential to contribute to the vigorous proliferation of lifethreatening viral infections such as HIV/AIDS. Consequently, a significant treatmentfocused 'harm reduction alliance' emerged. Consisting of various actors, mainly external to government, they lobbied for a more pragmatic drug policy, involving giving problematic drug users (PDUs) access to needle exchange schemes, making health education more available, supplying free condoms and introducing flexible prescribing of methadone (Robertson, 1987). Stimson (2000) refers to this as the 'health-phase' of UK drug policy, where drug related problems equated to issues pertaining to individual and public health.

The 1995 Drug Strategy initiated the reversal of this trend and ushered in what Stimson disparagingly terms the 'crime phase' of drug policy. Here drug harms are no longer viewed as a public-health problem but are intrinsically linked to criminality as drug-related crime came to be viewed as the primary scourge for families and communities (Hunt and Stevens, 2004). This consolidated criminal-justice control over UK drug policy. A central premise of the strategy was that PDUs were responsible for the majority of criminality in society with the suggestion that if drug users could be treated either voluntarily or through compulsion then crime rates would decline. This rhetoric has underpinned drug strategies ever since, representing a clear line of continuity. Alongside this, however, there have been a number of recognisable changes, which in the context of this paper relate to the methods proposed for tackling the problem of drug-related crime.

The first New Labour strategy emerged in 1998 followed by an updated version in 2002 and a successor document in 2008. The Coalition Government published their version in 2010. Over this 12 year period a creeping moralisation has re-emerged in social policy that has at its heart a specific desire to change the behaviour of specific 'problematic' populations without fully appreciating the underlying causes. This has filtered down into drug policy and the paper charts what this has meant for UK drug policy in theory if not practice, not least because policy developed at the national level often looks different on the ground and budgetary restraints can easily change the course of proposals. ${ }^{2} \mathrm{As}$ this is so, the current paper is organised in the following way. The next section takes a critical look at the link between drugs and crime. This followed by a discussion of New Labour's early drug strategy. Discussion then turns to New Labour's later documents and those of the Coalition. Finally some concluding comments are given.

\section{The embroidery of the drug-crime link}

The most widely cited explanation of the drugs-crime link is the tri-partite framework developed by Goldstein (1985). In this model he offered three different explanations for drug-related, violent offending:

- psychopharmacological - some substances have the capacity to change the functions of the brain, for example, by increasing aggression and inhibition 
- economic-compulsive - drug users are compelled to use drugs by addiction, this is funded by their criminal exploits

- systemic - illicit markets are inherently violent. Traffickers, dealers and users regulate their own affairs and have no recourse to national or international legal systems to do this.

Stevens (2011a) suggests that one reason for the longevity of the tri-partite framework is that it finds support on both sides of the drug legalisation debate. Those advocating continued prohibition, such as Inciardi (1991), use the psychopharmacological model to show how legalisation could bring about an increase in violent crime because it is likely to be accompanied by an associated rise in drug use. For others, the legalisation of substances will reduce crime as it takes away the systemic violence currently associated with illicit markets. Under the conditions of prohibition, the market is surrendered to various illegal syndicates who engage in gang crime to control their market share (Rolles et al., 2006).

Stevens (2007: 80) traces the drugs-crime link to official, government sponsored studies on both sides of the Atlantic' dating back to the 1980s. He states that despite warnings from one of their own colleagues (Mott, 1986), Home Office (1985) research has contributed to the 'exaggeration of the drugs-crime link' and this underpins many current debates. Indeed, the notion that most 'acquisitive' crime (crimes committed for some sort of financial gain such as shop lifting, burglary, robbery etc) or 'volume' crime (that which consumes large amounts of police time) are somehow drug related has become accepted wisdom. The drugs-crime nexus is now one of the most researched areas of drugs policy (e.g. Parker et al., 1988; MacGregor, 2000; Bennett and Holloway, 2005; 2009; Duke, 2006; Seddon, 2006) and is firmly established in the minds of policy-makers, politicians and the tabloid press none of whom have shied away from making such assertions. For instance, in 1994 Tony Blair calculated that half of the cost of all property thefts, some $£ 2$ billion pounds, could be attributable to drug users (Blair, 1994). This consolidated the view that prolonged use of substances such as heroin and cocaine was linked to frequent offending.

Following the maxim that if you say something enough it becomes true, in a speech some years later Blair commented that:

"The bulk of crime is committed by a hard core of persistent offenders, around 100,000 in all...These persistent offenders share a remarkably similar profile. Half are under 21. Nearly two-thirds are hard drug users. More than a third were in care as children. Half have no education at all. More than three-quarters were unemployed when they were offending" (Blair, 2001).

Economic analysis conducted by Godfrey et al., (2002) estimated that Class A drug users in England and Wales caused between $£ 9$ billion and $£ 16$ billion of social costs through their criminal activities in the year 2000. Stevens (2007: 81) demonstrates that these figures are reached by 'estimating the costs of recent crimes reported by drug users entering treatment in the National Treatment Outreach Research Study (NTORS)' and 'multiplying them by the estimated number of problem drug users'. In a similar vein, the drugs-crime link has been consolidated by the fact that the NEW-ADAM (New England and Wales Arrestee Drug Abuse Monitoring) found that 65 per cent of sampled arrestees had traces of drugs in their urine. The figures showed that the most common drug was cannabis, with 24 per cent testing positive for heroin and 15 per cent for cocaine (Stevens, 2007: 81) This has also been used by policy makers as proof of the drugs-crime link, despite repeated warnings from the author's themselves (Holloway and Bennett, 2004) that because of shortcomings over the methodology, it should not be used for this purpose. 
The problematic assumptions of the NTORS equations are put into focus by Stevens (2007) who demonstrates that drug users are more likely than non-drug users to be arrested for trigger offences such as acquisitive crimes. Therefore, studies of arrestees - on which government drug policies are based - are an exercise in 'voodoo criminology' to the extent that at best, they are methodologically flawed, and at worst they are fundamentally misleading. Such explanations, Stevens suggests, fail to account for the fact that a drug user's offending peaks just prior to the point of arrest as this coincides with the moment when help-seeking behaviour is most acute. This peak rate of offending is, however, taken as being indicative of the entire offending career of PDUs, thus greatly inflating the figures. Furthermore, there are also doubts about the nature of causality, not least because research has also proved inconclusive as to which activity occurs first for certain offenders; their initiation into drug taking or the onset of criminal behaviour.

Seddon (2006) has attempted to move the debate beyond a narrow causal discussion of drugs-related crime, by demonstrating how both problematic, chaotic drug use and significant amounts of criminality are linked to social disadvantage. The nature and extent of each is contingent on other factors such as (lack of) opportunities in the local formal economy which are counter-balanced by opportunities afforded to certain groups in the informal economy. For Seddon, these nuances are often overlooked in public debates which have tended to see the drugs-crime link as a historically 'natural' phenomenon and that the poorer members of society are somehow more predisposed to drug taking and criminality either out of fecklessness or greed.

As this brief overview demonstrates, the exact nature of the relationship between drugs and crime is, therefore, difficult to ascertain. Indeed, most people who currently use drugs or have used drugs in the past experience very few problems, either in terms of adverse health effects or brushes with authority. Although such statements generally relate to more 'recreational' drug use (Parker et al., 1998), a growing body of evidence shows that so-called 'harder' drugs can often be used in relatively un-problematic and controlled ways (Shewan and Dalgarno, 2005). In addition, research from a 'hidden' sample of drug users - that is those who have not been accessed via criminal-justice or treatment agencies - has demonstrated that heroin use is not always followed by criminal activity (Warburton et al., 2005). In short, there is little by the way of conclusive evidence of a causal link between drug use and criminality. Politicians and policy makers have, however, generally chosen to ignore this. As a consequence, it remains firmly part of the policy making firmament and has been the buttress on which the overarching drug strategies of successive governments since the 1990s have been built. That said, there has, over recent years, been incremental change in the way governments have attempted to regulate the behaviours of PDUs as we shall see.

\section{New Labour's Early Drug Strategy and Policy}

The passing of the 1998 Crime and Disorder Act which introduced the flagship New Labour Policy, the Drug Treatment and Testing Order (DTTO), was a pivotal moment in UK drug control in theory if not practice ${ }^{3}$. The DTTO featured heavily in their initial drug strategy, Tackling Drugs to Build a Better Britain (Cabinet Office, 1998 (updated in 2002)). It was implemented, in part, to counteract the perceived problem of high levels of acquisitive crime associated with problematic and chaotic drug use. invested the courts with powers to sentence mainly persistent offenders to a period of drug treatment if they so desired. The alternative was a custodial sentence. This is known as 'coercive' - or 'quasi-compulsory treatment (QCT). The 1998 drug strategy placed significant emphasis on increasing the total number of people in drug treatment, 
significantly expanding treatment services and making sure this was properly funded. For example, in the chapter specifically relating to drug treatment, the objective and targets are clearly spelt out. It states:

- Objective: to enable people with drug problems to overcome them and live healthy and crime-free lives

- Key performance target: to increase participation of problem drug misusers, including prisoners, in drug treatment programmes which have a positive impact on health and crime by 66 per cent by 2005 and by 100 per cent by 2008 (Cabinet Office, 1998: 21).

Hunt and Stevens (2004) chart the development of drugs policy at this time as a movement from voluntarism to coercion. Voluntarism describes a situation where a range of services are available to drug users, if required. These are underpinned by a harm reduction philosophy. Here the end goal is not necessarily for the user to become 'drug-free' - although if this is the desired outcome then steps would be put in place to assist - but to intervene to improve the social capital and health of the individual and the public in general. Coercive treatment, as outlined by the DTTO, is different. Here the state is empowered to employ various means to "track down drug users and lock them up if they do not comply' to undergo a period of drug treatment (Hunt and Stevens, 2004: 355). Seddon (2007) has commented on the ethical implications of coercing people into treatment, particularly if these services are delivered in part by the National Health Service (NHS). This process, he suggests, calls into question principles of patient consent and confidentiality which are the foundation stones on which treatment services have traditionally operated.

The rollout of the DTTO resonated with other aspects of New Labour governance; managerialism, performance audit, and joined-up service delivery under the guise of 'modernising' agenda (Senior et al., 2007). In drug treatment, various evaluations of QCT were carried out, but these have often been guilty of poor research design based on difficulties in assigning people into experimental and control groups, dealing with internal validity and coping with political interference in service delivery (see Stevens et al., 2005 for a comprehensive overview). Additionally, and as alluded to in the key performance target for drug treatment, it became difficult for evaluators to know 'what worked' in drug treatment and whether the goal of treatment was to reduce crime or improve the health and social capital of the drug user or both (Webster, 2007). This meant that the success of the policy was measured in terms of outputs - the amount of drug users entering treatment - rather than outcomes - what actually happened to the drug users once the treatment episode had been completed. A central tenet of drug treatment at this time involved supplying methadone to PDUs. Methadone is a kind of opioid replacement treatment. Its use has been advocated by those in the classic harm reduction tradition as well as those favouring the roll-out of QCT. There is much debate as to the efficacy of methadone treatment, particularly as part of coercive measures, but this is a complex policy debate. This is because methadone treatment may or may not be a key aspect of QCT interventions. Much evidence suggests that methadone maintenance treatment can help to reduce the criminality associated with heroin use and can lead to positive health gains. It can, furthermore, help to reduce heroin use in the short-term and can lead to abstinence in the long-term, but much depends on the treatment delivery and whether this is inpatient or in the community; with the former being seen as more efficient (Webster, 2007).

Critics have suggested, however, that one outcome of using methadone programmes as part of QCT in a bid to reduce offending is that it has had the obverse effect of its intended outcome. A report by the social care provider Turning Point (2004) 
stated that under the conditions of the DTTO, places on drug treatment programmes were increasingly allocated to those who had been coerced onto them to the detriment of those who wished to enter voluntarily. This created the perverse incentive that committing certain crimes was the most effective means of accessing treatment services. There is, however, little concrete evidence for this and other research has shown that the success of drug treatment or otherwise depends on the motivations of the offender, which, in turn, is contingent on factors such as whether legal pressure is applied to treatment, the length of the treatment episode, medical status, employment/support status, levels of drug/alcohol use, family and social relationships and psychiatric status (Stevens et al., 2006).

There is some evidence that quasi-compulsory methadone maintenance treatment has produced some positive results. A recent report by the National Treatment Agency (2009) suggests that heroin users who are prescribed methadone reduce their offending by up to a half whilst engaged in treatment. Such findings must, however, be offset against those that feel it does so by prolonging drug dependency (Gyngell, 2007) or that focusing on crime reduction does not deal with underlying problems of poverty and inequality that may be the cause of drug dependency in the first instance (Stevens, 2011a).

As New Labour moved into their third term, it became clear that scepticism surrounding the efficacy of methadone treatment was gaining momentum. Thus, criticisms of methadone maintenance from Gyngell and the Centre for Policy Studies of which she is a part, resonated clearly with the Brown government who were increasingly disillusioned with the perceived inability of drug treatment services to help drug users overcome their addictions (Stevens, 2011a). This, in combination with a range of other issues, brought about an evolution in later New Labour's thinking about drugs.

\section{From New Labour to the Coalition: 2008 and Beyond}

It is a key assertion of this paper that there is a broad political consensus that a vast proportion of criminality is drug related and that communities need to be protected from the scourge of drug-related crime. Recently there have been subtle changes in the policies proposed to deal with this situation. Whereas the 1998 strategy placed great store in 'containing' drug users on maintenance programmes, simultaneously attempting to reduce their criminality, the later New Labour strategy Drugs: Protecting Families and Communities (Home Office, 2008) advocated a more explicit attempt to foster behavioural change amongst PDUs. Underpinning this has been an increasing use of conditionality in the benefits system (Dwyer, 2004) and the concomitant notion that with rights come responsibilities.

The subtle contrast between the early and later New Labour drug strategies can be brought into focus with the following passages from the 2008 strategy:

"The Home Office, Ministry of Justice, prosecutors, police and partners will continue to present drug-misusing offenders with tough choices to change their behaviour or face the consequences" (Home Office, 2008: 16)

Later in the same document under a sub-heading entitled 'Our New Approach', it states:

"The goal of all treatment is for drug users to achieve abstinence from their drug

- or drugs - of dependency. For some, this can be achieved immediately, but 
many others will need a period of drug-assisted treatment with prescribed medication first" (Home Office, 2008: 28).

These key passages reveal an ongoing commitment to maintenance in the shortterm, but breaking with recent tradition, highlight a commitment to abstinence in the long-term as a form of behavioural change. For Wincup (2011: 22), this was a product of concern that large numbers of drug users - estimated to be in the region of 100,000 - were claiming benefits, but not addressing their drug dependency. It was, furthermore, part of broader developments in New Labour's social policies, where support and discipline were increasingly intertwined to the end that work, where applicable, would be the desired goal for everyone. Under proposals outlined by a Department of Work and Pensions (DWP) (2008) Green Paper published shortly after the 2008 drug strategy, a series of incentives (carrots) and requirements (sticks) were promoted to enable dependent drug users to avoid the 'sin' of 'worklessness'. Taken together, the carrots included providing additional support for those committed to drug treatment programmes. The main stick, meanwhile, included the potential to remove benefits for those who took no action in addressing their drug problem (DWP, 2008: 48-50).

The promotion of abstinence was very much a line of continuity between later New Labour strategies and the current Coalition approach. It featured prominently in early Coalition publications for dealing with the drug problem. Thus the Programme for Government contains the following paragraph:

"We will conduct a full review of sentencing policy to ensure that it is effective in deterring crime, protecting the public, punishing offenders and cutting reoffending. In particular, we will ensure that sentencing for drug use helps offenders come off drugs..." (Cabinet Office, 2010: 21)

Other documents published around this time developed these themes, but chose to focus on 'recovery' from drug dependency rather than abstinence, although the two terms were often conflated. In the Ministry of Justice Green Paper (2010) Breaking the Cycle, the aim to get drug dependent offenders off substance misuse and into recovery featured prominently in its 'rehabilitation revolution'. Seemingly, the Coalition initially had a clear view about how recovery could best be achieved. Drawing on some of the ideas previously espoused by the Centre for Social Justice Think Tank and their belief that methadone maintenance is 'madness' that doesn't work, this document proposed a heightened role for residential rehabilitation services (Gyngell, 2007). Although residential rehabilitation services have had some success in the treatment of drug addiction, there is a significant basic economic limitation to this solution. According to Stevens (2011b), it costs around $£ 26,000$ per person per year to undergo residential rehabilitation treatment in comparison to the $£ 2,020$ it costs to run a methadone maintenance programme over the same duration. In times of austerity, how the roll-out of residential rehabilitation places will be funded remains unclear.

Initially, then, recovery equated to abstinence in coalition documents, but the abstinence rhetoric has since been toned down (Travis, 2010). The commitment to recovery still serves as a condition for drug users requiring financial support from the state. The Coalition drug strategy Reducing Demand, Restricting Supply and Building Recovery Supporting People to Live a Drug Free Life (Home Office, 2010) thus states:

"We will create a recovery system that focuses not only on getting people into treatment and meeting process-driven targets, but getting them into full recovery and off drugs and alcohol for good. It is only through this permanent change that individuals will cease offending, stop harming themselves and their communities and successfully contribute to society" (Home Office, 2010: 18) 
It is unclear what the 'process-driven targets' will entail, other than them involving some kind of 'payment-by-results'. Recovery is, however, defined in the strategy as involving 'three overarching principles - wellbeing, citizenship, and freedom from dependence. It is an individual, person-centred journey, as opposed to an end-state, and one that will mean different things to different people' (Home Office, 2010: 18). This strategy also suggests that recovery will help to develop social, physical, human and cultural capital; a list that together constitutes the 'recovery capital' of the individual. Enhancing recovery capital is to be achieved through supporting services to 'work with individuals to draw on this capital in their recovery journey' (Home Office, 2010: 19). Although in need of elaboration, none is forthcoming, but like the 2008 strategy it does continue to place significant emphasis on trying to change the behaviours of problematic populations through the benefits system and like all previous strategies it is wedded to the idea that most crime is drug-related.

Wincup (2011) notes that under proposals outlined in the Coalition drug strategy carrots and sticks will continue to be employed to ensure drug users are 'nudged' (read cajoled) towards drug treatment. Stevens (2011b), meanwhile, shows that for drug users to obtain this recovery capital then investment in specific services is the order of the day, not least those which provide access to quality, affordable housing. This used to be overseen by investing in early intervention schemes for housing vulnerable groups and families. As it stands, proposed changes to housing benefit, proposed in the Welfare Reform Bill are likely to impact precisely on the poorest who are forced to uproot and relocate to cheaper areas with smaller dwellings where, in all likelihood, there are pre-existing social problems such as high unemployment, high crime and little access to effective health or social care services; a situation noted as being a good indicator for the onset of, or return to, drug use (Pearson, 1987; Seddon, 2006).

In essence, valorising work through active labour market strategies and increasing conditions on welfare benefit payments has underpinned UK drug policy since 2008 . It was intended to bring about change in the behaviour of problematic populations through a combination of incentives and increased surveillance; a process Harrison (2010) has suggested contributes towards a 'new behaviourism' in social policy. The shift towards making individuals become drug-free is more prominent in recent drug strategies as the philosophy of containment has waned. For some thinkers, these developments are a step in the right direction and are morally correct. Indeed, McKeganey (2011) suggests that there has hitherto been a noticeable absence of any mention of the morality of drug taking from drug strategies, which has begun to change. He suggests that taking a moral stance such as stigmatising certain behaviours can have positive benefits for society in that questioning the morality of certain dangerous activities has been a useful tool in curbing their prevalence. He cites the example of drink-driving campaigns here where "stigma has been used as a marketing strategy to encourage the view that those who drink and drive are socially irresponsible' (McKeganey, 2011: 168).

Various authors are sceptical of the increasing moral dimension to UK drug policy and the heightened emphasis on behavioural change (e.g. Nutt and Macken, 2011; Stevens 2011b). This is primarily on the grounds that the focus on abstinence/recovery in terms of treatment creates fundamental problems, not least that withdrawing benefits from those most in need can cause more problems than it solves and that abstinence should be a choice rather than an imposition. In addition, it is not clear whether UK drug policy has lacked a moral dimension. In light of the contested evidence-base for such assertions, assuming that a high proportion of PDUs are responsible for a non-trivial amount of criminality is precisely a moral standpoint, as is the desire to move away from methadone maintenance as part of the treatment package on the grounds of its lack of success. 


\section{Conclusion}

There are clear lines of continuity spanning the UK Government drug strategies since the 1990s. All have a primary concern with reducing drug-related crime, despite the fact that the evidence-base for such a policy remains contested. It is the central contention of this paper that clear points of departure can also be witnessed between New Labour's initial approaches and those that followed. These changes are underpinned by a belief in behaviourism. For PDUs this means that benefits are increasingly contingent on engaging with drug treatment programmes and demonstrating a commitment to move beyond maintenance towards recovery. Yet the potential for recovery is hindered by a lack of clarity over what it entails and cuts to services that would appreciably positively impact on the life chances of PDUs. Early signs from the coalition were that cuts to these services may be offset by the rollout of more residential rehabilitation centres, but as has been demonstrated they have yet to square the circle of how these are to be funded. All of which leaves something of a question mark over where UK drug policy is heading and ultimately reinforces the point that where drug strategies and policy is concerned the rhetoric is always clearer than the reality.

\section{Notes}

1 Although purporting to cover the whole of the UK and/or Britain, in reality, the devolved administrations have developed their own policies in relation to their own strategies. With this proviso in mind, this article looks at how UK drug strategies have evolved since 1995 referring mainly to the situation in England.

2 In short, it is necessary to comment that policy on paper is not always the same as policy in practice and that the 'implementation gap' (e.g. Dickinson, 2011) must be acknowledged.

3 As Stevens (2011:71) demonstrates, the DTTO was rarely used. It was, however, the first time drug dependent individuals could be sentenced to treatment by the courts. It was replaced in 2005 by the Drug Rehabilitation Requirement (DRR), although the two policies are very much of the same lineage acting as alternatives to imprisonment in the first instance (see McSweeney et al, 2007).

\section{Acknowledgements}

Thanks to Emma Wincup and Simon Prideaux for their comments on an earlier draft of this paper. The usual disclaimers apply.

* Correspondence address: Dr Mark Monaghan, School of Sociology and Social Policy, University of Leeds, Woodhouse Lane, Leeds, LS2 9JT. Email: m.p.monaghan@leeds.ac.uk. 
p. 38. The Recent Evolution of UK Drug Strategies: From Maintenance to Behaviour Change?

\section{References}

Advisory Council on the Misuse of Drugs (ACMD) (1988) AIDS and Drug Misuse, London: Home Office.

Bean, P. (2004) Drugs and Crime, $2^{\text {nd }}$ edition. Cullumpton: Willan.

Bennett, T. and Holloway, K. (2005) Understanding Drugs, Alchol and Crime. Buckingham: Open University Press.

Bennett, T. and Holloway, K. (2009) The Causal Connection Between Drug Misuse and Crime. British Journal of Criminology, 49, 3, 513-531.

Blair, T. (1994) Drugs: the need for action. News release, Labour party.

Blair, T. (2001) Speech by the Prime Minister at the Peel Institute, 26 January, 2001, available online at http://webarchive.nationalarchives.gov.uk/2006100 4085342/number10.gov.uk/page1577

Cabinet Office (1998) Tackling Drugs to Build a Better Britain. London: HMSO.

Cabinet Office (2010) The Coalition: Our Programme for Government. London: Cabinet Office.

Department of Health (1995) Tackling Drugs Together. London: Department of Health.

Department of Work and Pensions (2008) No One Written Off: Reforming Welfare to Reward Responsibility. London: The Stationary Office.

Dickinson, H. (2011) Implementing policy' in: J. Glasby (ed) Evidence, Policy and Practice: Critical Perspectives in Health and Social Care. Bristol: Policy Press.

Dorn, N., Murji, K. and South, N. (1992) Traffickers: Drug Markets and Law Enforcement. London: Routledge.

Duke, K. (2006) Out of crime and into treatment? The criminalization of contemporary drug policy since Tackling Drugs Together. Drugs: Education, Prevention and Policy, 13, 5, 409-15.

Dwyer, P. (2004) Creeping conditionality in the UK: from welfare rights to conditional entitlements. Canadian Journal of Sociology, 29, 2, 265-287.

Godfrey, C. Eaton, G., McDougall, C. and Culyer, A. (2002) The Economic and Social Costs of Class A Drug Use in England and Wales, 2000, Home Office Research Study 249. London: Home Office.

Goldstein, P. (1985) The drugs-violence nexus: A tripartite framework. Journal of Drug Issues, 15, 493-506.

Gyngell, K. (2007) Breakthrough Britain: Ending the Costs of Social Breakdown: Volume 4: Addictions. London: Conservative Party.

Harrison, M. (2010) The 'new behaviourism' versus the 'real third way': some failures of UK social policy and of social policy academics? Paper presented to the Social Policy Association Conference, University of Lincoln, UK (July 2010).

Holloway, K. and Bennett, T. (2004) The Results of the First Two-Years of the NEWADAM Programme. London: The Home Office, available online at http://www.homeoffice.gov.uk/rds/pdfs04/rdsolr1904.pdf

Home Office (1985) Tackling Drug Misuse: A Summary of the Government's Strategy. London: Home Office.

Home Office (2008) Drugs: Protecting Families and Communities. The 2008-2018 Drug Strategy. London: Home Office.

Home Office (2010) Drug Strategy 2010: Reducing Demand, Restricting Supply and Building Recovery: Supporting People to Live a Drug Free Life. London: Home Office.

Hughes, R. and Anthony, N. (2006) Drugs, crime and criminal justice, in: R. Hughes, R. Lart and P. Higate, Drugs: Policy and Politics. Maidenhead: Open University Press.

Hunt, N. and Stevens, A. (2004) Whose harm? Harm reduction and the shift to coercion in UK drug policy. Social Policy and Society, 3, 4, 333-342.

Inciardi, J. (ed.) (1991) The Drug Legalization Debate. London: Sage. 
p. 39. The Recent Evolution of UK Drug Strategies: From Maintenance to Behaviour Change?

MacGregor, S. (2000) Editorial: The drugs-crime nexus. Drugs: Education, Prevention and Policy, 7, 4, 311-16.

McKeganey, N. (2011) Controversies in Drugs Policy and Practice. Basingstoke: Palgrave Macmillan.

McSweeney, T., Hough, M. and Turnbull, P. (2007) Drugs and crime: Exploring the links, in: M. Simpson, T. Shildrick and R. MacDonald (eds.) Drugs in Britain: Supply, Consumption and Control. Basingstoke: Macmillan.

Ministry of Justice (2010) Breaking the Cycle: Effective Punishment, Rehabilitation and Sentencing of Offenders. London: Ministry of Justice.

Mott, J. (1986) Opioid use and burglary. British Journal of Addiction, 81, 5, 671-7.

National Treatment Agency (2009) Breaking the Link: The Role of Drug Treatment in Tackling Crime. London: National Treatment Agency for Substance Abuse.

Newcombe, R. (2007) Trends in the prevalence of illicit drug use, in: M. Simpson, T. Shildrick and R. MacDonald (eds) Drugs in Britain: Supply, Consumption and Control. Basingstoke: Macmillan.

Nutt, D. and Macken, S. (2011) Same difference? Evidence versus 'common sense' in the Coalition Drug strategy. Criminal Justice Matters, 84, 1, 12-13.

Parker, H., Bakx, K. and Newcombe, R. (1988) Living With Heroin: The Impact of a Drugs "Epidemic" on an English Community. Milton Keynes: Open University Press.

Parker, H., Aldridge, J. and Measham, F. (1998) Illegal Leisure: The Normalization of Adolescent Recreational Drug Use. London: Routledge.

Pearson, G. (1987) The New Heroin Users. London: Blackwell.

Robertson, R. (1987) Heroin, AIDS and Society. London: Hodder Stoughton.

Rolles, S., Kushlick, D. and Jay, M. (2006) After the War on Drugs: Options for Control. Bristol: Transform Drug Policy Foundation.

Seddon, T. (2006) Drugs, crime and social exclusion: Social context and social theory in British Drugs-Crime Research. British Journal of Criminology, 46, 4, 680-703.

Seddon, T. (2007) The hardest drug? Trends in heroin use in Britain, in: M. Simpson, T. Shildrick and R. MacDonald (eds) Drugs in Britain: Supply, Consumption and Control. Basingstoke: Macmillan.

Senior, P., Crowther-Dowey, C. and Long, M. (2007) Understanding Modernisation in Criminal-Justice. Buckingham: Open University Press.

Shiner, M. (2003) Out of harm's way? Illicit drug use, medicalization and the Law. The British Journal of Criminology, 43, 4, 772-796.

Shewan, D. and Dalgarno, P. (2005) Evidence for controlled heroin use? Low levels of negative health and social outcomes among non-treatment heroin users in Glasgow (Scotland). British Journal of Health Psychology, 10, 1, 33-48.

Stevens, A. (2007) When two dark figures collide: evidence and discourse on drug related crime. Critical Social Policy, 27, 1, 77-99.

Stevens, A. (2011a) Drugs, Crime and Public Health: The Political Economy of Drug Policy. London: Routledge.

Stevens, A. (2011b) Recovery through contradiction? Criminal Justice Matters, 84, 1, 20-21.

Stevens, A., Berto, D., Heckman, W., Kerschl, V., OeuvrayK., Van Ooyen, M., Steffan, E. and Uchtenhagen, A. (2005) Quasi-Compulsory Treatment of Drug Dependent Offenders: An International Literature Review. Substance Use and Misuse, 40, 3, 269-83.

Stevens, A., Berto, D., Frick, U., Hunt, N., Kerschl, V., McSweeney, T.Oeuvray, K., Puppo, I., Santa Maria, A., Schaaf, S. Trinkl, B., Uchtenhagen, A. and Werdenich, W. (2006) The relationship between legal status, perceived pressure and motivation in treatment for drug dependence: Results from a European Study of QuasiCompulsory Treatment. European Journal of Addiction Research, 12, 4, 197-209. 
Stimson, G. (2000) Blair declares war: The unhealthy state of British drug policy. International Journal of Drug Policy, 11, 4, 259-64.

Travis, A. (2010) Coalition shelves plans for 'abstinence-based' drug strategy. The Guardian, Wednesday December, 8 available online at http://www.guardian.co.uk/uk/2010/dec/08/coalition-drugs-strategyabstinence-recovery accessed November 8, 2011

Turning Point (2004) Routes into Treatment. London: Turning Point.

Warburton, H., Turnbull, P.J. and Hough, M. (2005) Occasional and Controlled Heroin use: Not a Problem? York: Joseph Rowntree Foundation.

Webster, C. (2007) Drug treatment, in: M. Simpson, T. Shildrick and R. MacDonald (eds) Drugs in Britain: Supply, Consumption and Control. Basingstoke: Macmillan.

Wincup, E. (2011) Carrots and sticks: problem drug users and welfare reform. Criminal Justice Matters, 84, 1, 22-23. 